Tersedia Online di http://journal2.um.ac.id/index.php/jmsp/

ISSN Online : 2541-4429

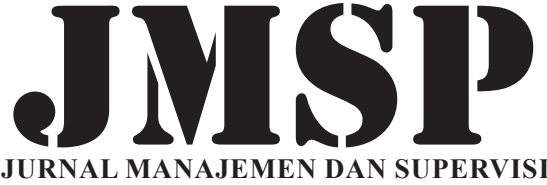

PENDIDIKAN

\title{
PERAN KEPEMIMPINAN VISIONER KEPALA SEKOLAH HUBUNGANNYA DENGAN KESIAPAN GURU MENYONGSONG REVOLUSI INDUSTRI 4.0
}

\author{
Mustiningsih; Maisyaroh; Nurul Ulfatin
}

\author{
Universitas Negeri Malang, Jalan Semarang No. 5 Malang Jawa Timur Indonesia \\ mustiningsih.fip@um.ac.id
}

\begin{abstract}
The purpose of this research is to find out, (1) the level of visionary role of the principal's visionary leadership, namely the reconstruction of policies, direction determinants, change agents, spokespersons, and trainers as well as the teacher's readiness variable to meet the industrial revolution 4.0, (2) the relationship between the role of the principal's leadership in reconstructing the policy towards teacher readiness, (3) the relationship between the variables determining the direction of the teacher's readiness, (4) the relationship of the agent of change variables to the teacher's readiness, (5) the relationship of the speaker variable to the teacher's readiness, (6) the relationship of the coach's variable to the teacher's readiness, (7) the relationship between the principal's leadership role in reconstructing policies, directors, change agents, spokespersons, and trainers simultaneously with teacher readiness. This study uses a quantitative approach in the effective SDN Malang. Data collection techniques with a closed questionnaire, using central tendency analysis and path analysis.
\end{abstract}

Keywords: visionary leadership, teacher readiness, industrial revolution 4.0

\begin{abstract}
Abstrak: Tujuan penelitian untuk mengetahui, (1) tingkat variabel peran kepemimpinan visioner kepala sekolah yakni perekonstruksi kebijakan, penentu arah, agen perubahan, juru bicara, dan pelatih serta variabel kesiapan guru menyongsong revolusi industri 4.0, (2) hubungan peran kepemimpinan kepala sekolah dalam merekonstruksi kebijakan terhadap kesiapan guru, (3) hubungan variabel penentu arah terhadap kesiapan guru, (4) hubungan variabel agen perubahan terhadap kesiapan guru, (5) hubungan variabel juru bicara terhadap kesiapan guru, (6) hubungan variabel pelatih terhadap kesiapan guru, (7) hubungan antara peran kepemimpinan kepala sekolah dalam merekonstruksi kebijakan, penentu arah, agen perubahan, juru bicara, dan pelatih secara simultan dengan kesiapan guru. Penelitian ini menggunakan pendekatan kuantitatif di SDN efektif Kota Malang. Teknik pengumpulan data dengan angket tertutup, menggunakan analisis tendensi sentral dan analisis path.
\end{abstract}

Kata Kunci: kepemimpinan visioner, kesiapan guru, revolusi industri 4.0

Perkembangan organisasi pada setiap jaman menuntut karakteristik kepemimpinan tertent. Perkembangan teori kepemimpinan telah banyak dimunculkan oleh para pakar, antara lain: kepemimpinan karismatik, kepemimpinan militeristik, kepemimpinan situasional, kepemimpinan transformasional, hingga kepemimpinan visioner [1]. Dari berbagai gaya kepemimpinan yang ada, gaya kepemimpinan yang dianggap paling berdampak efektif untuk menjawab tantangan era revolusi indstri 4.0 adalah gaya kepemimpinan visioner [2]. Sebab kepemimpinan visioner dianggap sebagai salah satu gaya kepemimpinan yang paling efektif dalam menghadapi tantangan perubahan yang terjadi di era globalisasi yang sarat dengan perubahan [3].

Pada era revolusi industry 4.0 kepemimpinan secara umum menghadapi dua isu yang juga menjadi tantangan global, yakni cross-cultural management dan change management. Cross-cultural management diperlukan dalam upaya memberikan pemahaman menjembatani hambatan organisasi dan berbagai implikasi budaya. Change management memberikan konsep untuk memahami dinamika dan berbagai manuver dalam budaya organisasi untuk menyesuaikan diri dengan perubahan lingkungan.

Pimpinan pada masa sekarang menghadapi lingkungan yang cepat berubah dengan percepatan yang belum pemah terjadi sebelumnya [4]. Melakukan pembelajaran berarti menetapkan strategi inovasi, 
perbaikan berkelanjutan, dan komitmen terhadap tugas dan tujuan organisasi [5]. Organisasi pembelajar merupakan lingkungan yang kondusif bagi aktivitas kepemimpinan visioner, karena dapat tercipta iklim kerjasama yang sinergi antar sub sistem dalam organisasi sehingga anggota organisasi memiliki komitmen, integritas dan tanggung jawab secara kolektif terhadap keseluruhan kinerja organisasi.

Dengan melihat kenyataan lingkungan organisasi yang terus mengalami perubahan, maka peran pemimpin tidak hanya berusaha menyesuaikan organisasi terhadap pergerakan inovasi di luar, akan tetapi pemimpin yang berhasil apabila mampu membawa organisasi sebagai referensi bagi institusi lainnya [6]. Sehingga agar dapat mewujudkan organisasi yang efektif dan kompetitif, sehingga kekuatan kepemimpinan menghasilkan berbagai kebijakan dalam pelayanan publik. Yang tidak kalah pentingnya adalah menyiapkan para guru menyongsong era revolusi industry 4.0 agar dapat menjalan tugas mengoptimalkan pembelajaran dengan lebih baik [7]. Tantangan yang dihadapi dunia pendidikan pada era revolusi industri 4.0 antara lain terkait dengan kemampuan guru mengembangkan inovasi untuk meningkatkan hasil pembelajaran [8]. Di antara tantangan tersebut berupa tantangan sosial yang meliputi perubahan demografi dan nilai sosial, peningkatan kerja virtual, dan pertumbuhan kompleksitas proses.

Memasuki era revolusi industri 4.0 terdapat permasalahan yang harus diselesaikan sesuai dengan eranya. Hal ini dimaksudkan agar tidak ada atau meminimalkan ketidaktercapaian tujuan pendidikan atau tujuan pembelajaran dalam rangka menyiapkan generasi yang mampu bertahan dalam kompetisi di era revolusi industri 4.0 [9]. Lebih lengkap Menteri riset, teknologi dan pendidikan tinggi Republik Indonesia (2019) menyatakan bahwa dalam menghadapi reolusi industri 4.0 perlu disiapkan yaitu kepala sekolah lebih sering mengadakan supervisi; rekonstruksi kebijakan, dan responsif serta adaptif terhadap perubahan yang terjadi; persiapan sumber daya manusia yang responsif, adaptif dan handal; pengadaan sarana dan prasarana yang mendukung adanya IT yang handal sesuai dengan era revolusi industri 4.0.

Guna mengantisipasi masalah yang bisa timbul dan guna mempersiapkan guru di era revolusi industri 4.0, diperlukan optimalisasi peran kepemimpinan visioner kepala sekolah yang ditandari antara lain memiliki kegesitan, kecepatan serta mampu beradaptasi dalam membawa jalannya organisasi memiliki peran yang penting dalam menghadapi kondisi organisasi yang senantiasa mengalami perubahan [11]. Sebab, fleksibilitas organisasi pada dasarnya merupakan karya orang-orang yang mampu bertindak proaktif, kreatif, inovatif dan non konvensional. Pribadi-pribadi seperti inilah yang dibutuhkan sebagai pemimpin organisasi pada era revolusi idustri 4.0. Seorang pemimpin adalah inspirator perubahan dan visioner, yaitu memiliki visi.

Menyongsong revolusi industri 4.0 tidak lepas dari peran guru sebagai pendidik di sekolah efektif. Komponen sekolah yang efektif dilandasi oleh penyelenggaraan pembelajaran yang profesional yang ditunjang oleh 7 komponen yakni: (1) intensitas monitoring kemajuan belajar siswa, (2) keadaan sarana dan prasarana, (3) pemberian kesempatan siswa untuk belajar dan mengerjakan tugas, (4) penciptaan iklim kerja yang kondusif, (5) kejelasan misi sekolah, (6) hubungan dengan masyarakat yang positif, dan (7) kepemimpinan pembelajaran yang kuat [12]. Berdasarkan pendapat ini sekolah yang efektif antara lain ditandai dengan adanya pemberian kesempatan belajar yang luas bagi siswa, penciptaan iklim kerja yang kondusif, dan kepemimpinan yang kuat dan yang lebih sesuai adalah kepemimpinan visioner.

Terdapat beberapa sekolah dasar negeri di kota Malang yang dapat dikategorikan sekolah efektif yang sering pula disebut sebagai sekolah rujukan, sekolah unggul atau sekolah model. Sebagai sekolah rujukan, diperlukan memiliki kepala sekolah visioner dan guru yang siap menyongsong revolusi industry 4.0. Hal ini dimaksudkan sebagai pionir bagi sekolah lain dan dalam rangka meningkatkan daya saing sekolah di era digital.

\section{METODE}

Penelitian ini menggunakan pendekatan kuantitatif. Penelitian kuantitatif merupakan metode untuk menguji teori dengan cara meneliti hubungan antar variable [13], [14]. Rancangan penelitian ini adalah 
korelasional dengan jenis expost facto. Peneliti tidak mengontrol secara langsung variabel bebas karena kegiatannya telah terjadi. Populasi penelitian ini adalah Sekolah Dasar Negeri Efektif atau Unggulan di kota Malang Jawa Timur. Sampel diambil dengan teknik purposive random sampling. SDN efektif di kota Malang sejumlah 20 SDN. Dengan total responden per sekolah 1 Kepala Sekolah dan 6 guru sehingga ditemukan total responden sebanyak 140 responden.

Instrumen yang digunakan untuk pengumpulan data penelitian yakni berupa angket (tertutup). Angket tertutup yakni kuesioner yang disusun dengan menyediakan pilihan jawaban lengkap, sehingga responden dapat memilih jawaban yang dirasa tepat [15], [16]. Dalam SEM ditegaskan bahwa sampel harus lebih dari 100 untuk memberikan kekuatan statistik yang memuaskan [17], [18], dengan demikian menurut pendapat tersebut ukuran sampel dianggap dapat diterima untuk penelitian ini.Instrumen pengumpulan data penelitian ini menggunakan angket tertutup. Angket dikembangkan berdasarkan teori yang melandasi variabel-variabel penelitian ini. Variabel penelitian dikembangkan menjadi sub variabel dan indikator, selanjutnya dijabarkan berupa butir-butir pernyataan yang dapat mengukur variabel penelitian.

Analisis data menggunakan ukuran tendensi sentral dan analisis jalur path. Sejalan dengan tujuan penelitian, peneliti menggunakan bantuan aplikasi SPSS 24.0 untuk analisis deskriptif dan AMOS 24.0 untuk CFA dan regresi berganda. Tujuan dari penelitian ini yakni untuk mengetahui pengaruh variabel peran kepemimpinan visioner kepala sekolah (X), perekontruksi kebijakan (X1), penentu arah (X2), agen perubahan (X3), juru bicara (X4), dan pelatih (X5) terhadap kesiapan guru menyongsong revolusi industri 4.0 (Y). Model kerangka teoritis pada penelitian ini dapat dilihat pada Gambar 1. Pemodelan persamaan struktural SEM dilakukan menggunakan SEM AMOS 24.

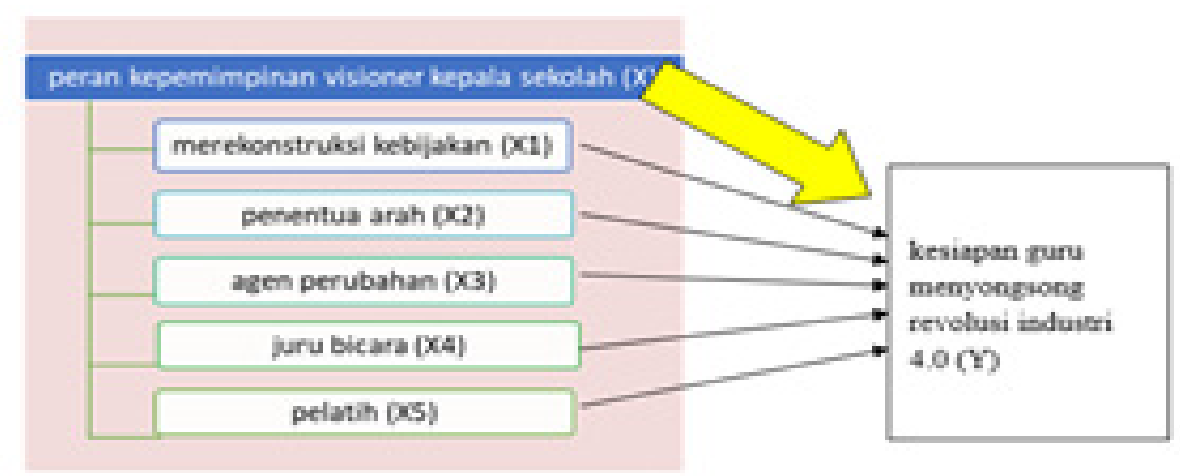

\section{HASIL}

\section{Karakteristik Responden}

Karakteristik responden (jenis kelamin, usia, masa kerja, dan karakteristik responden) ditunjukkan pada Tabel 1. Persentase responden perempuan 62,14\% lebih dari responden laki-laki 37,86\%. Karakteristik responden berdasarkan usia persentase yang paling besar adalah $>45$ tahun yakni 32,86 $\%$, selanjutnya 25 - 35 tahun 29,29\%, 36-45 tahun 23,57\% dan $<25$ tahun 14,29 \%. Karakteristik responden berdasarkan masa kerja persentase yang paling besar adalah $>14$ tahun yakni 35,71\%, selanjutnya 0-4 tahun 24,29\%, 5-9 tahun 20,71\%, dan 10-14 tahun 19,29 \%. Sedangkan karakteristik responden berdasarkan pendidikan terakhir persentase yang paling besar adalah responden S-1 80,71\% lebih dari responden S2 17,86\%, selanjutnya SMA Sederajat 4,29\%, D-III sebesar 1,43\%, dan responden D-I, D-II, serta S-3 0\%. 
Tabel 1. Statistik Karakteristik Responden

\begin{tabular}{llcc}
\hline Group & Characteristic & Frequency & Percentage \\
\hline Jenis Kelamin & Laki-Laki & 53 & $37,86 \%$ \\
Usia & Perempuan & 87 & $62,14 \%$ \\
& $<25$ Tahun & 20 & $14,29 \%$ \\
& 25-35 & 41 & $29,29 \%$ \\
Masa Kerja & 36-45 & 33 & $23,57 \%$ \\
& $>$ 45 Tahun & 46 & $32,86 \%$ \\
& 0-4 Tahun & 34 & $24,29 \%$ \\
& 5-9 Tahun & 29 & $20,71 \%$ \\
Pendidikan Terakhir & 10-14 Tahun & 27 & $19,29 \%$ \\
& $>14$ Tahun & 50 & $35,71 \%$ \\
& SMA Sederajat & 6 & $4,29 \%$ \\
& D-I & 0 & $0,00 \%$ \\
& D-II & 0 & $0,00 \%$ \\
& D-III & 2 & $1,43 \%$ \\
& S-1 & 113 & $80,71 \%$ \\
S-2 & 25 & $17,86 \%$ \\
& S-3 & 0 & $0,00 \%$ \\
\hline
\end{tabular}

\section{Deskripsi Data}

Hasil analisis deskriptif pada penelitian ini meliputi Variabel peran kepemimpinan visioner kepala sekolah yakni perekontruksi kebijakan (X1), penentu arah (X2), agen perubahan (X3), juru bicara (X4), pelatih (X5) dan variabel kesiapan guru dalam menyongsong RI 4.0 (Y). Hasil deskriptif secara keseluruhan untuk semua variabel ditunjukkan pada dalam Tabel 2.

Tabel 2. Hasil Analisis Deskriptif Statistik

\begin{tabular}{lrrrrrr}
\hline & $\begin{array}{c}\text { Perekontruksi } \\
\text { Kebijakan }\end{array}$ & $\begin{array}{c}\text { Penentu } \\
\text { Arah }\end{array}$ & $\begin{array}{c}\text { Agen } \\
\text { Perubahan }\end{array}$ & $\begin{array}{c}\text { Juru } \\
\text { Bicara }\end{array}$ & Pelatih & \multicolumn{1}{c}{$\begin{array}{c}\text { Kesiapan } \\
\text { Guru }\end{array}$} \\
\hline N Valid & 140 & 140 & 140 & 140 & 140 & 140 \\
$\quad$ Missing & 0 & 0 & 0 & 0 & 0 & 0 \\
Mean & 39,1571 & 55,9429 & 49,3857 & 35,3571 & 48,4286 & 120,9286 \\
Std. & 4,43218 & 6,53686 & 5,51203 & 3,79525 & 5,75413 & 10,66875 \\
Deviation & & & & & & \\
Range & 17,00 & 26,00 & 23,00 & 15,00 & 23,00 & 53,00 \\
Minimum & 27,00 & 38,00 & 33,00 & 25,00 & 33,00 & 87,00 \\
Maximum & 44,00 & 64,00 & 56,00 & 40,00 & 56,00 & 140,00 \\
\hline
\end{tabular}

Berdasarkan Tabel 2 dapat dijelaskan bahwa variabel perekonstruksi kebijakan diperoleh mean sebesar 39,16 dengan standar deviasi sebesar 4,43, variabel penentu arah diperoleh mean sebesar 55,94 dengan standar deviasi sebesar 6,54, variabel agen perubahan diperoleh mean sebesar 49,39 dengan standar deviasi sebesar 5,51, variabel juru bicara diperoleh mean sebesar 35,36 dengan standar deviasi 3,80 , variabel pelatih diperoleh mean sebesar 48,43 dengan standar deviasi 5,75 dan variabel kesiapan guru menyongsong RI 4.0 diperoleh mean sebesar 120,93 dengan standar deviasi 10,67.

Secara rinci untuk distribusi frekuensi deskripsi masing-masing variabel dijelaskan sebagai berikut.

Tabel 3. Distribusi Frekuensi Variabel Perekonstruksi Kebijakan (X1)

\begin{tabular}{ccc|c}
\hline No. & Kategori & Interval & Frekuensi \\
\hline $\mathbf{l}$ & Sangat Baik & $38-46$ & 102 \\
$\mathbf{2}$ & Baik & $29-37$ & 34 \\
$\mathbf{3}$ & Kurang Baik & $20-28$ & 4 \\
$\mathbf{4}$ & Tidak Baik & $11-19$ & 0 \\
\hline
\end{tabular}


Berdasarkan Tabel 3 dapat dijelaskan bahwa tingkat variabel perekonstruksi kebijakan diperoleh kriteria sangat baik dengan frekuensi 102 responden, baik 34 responden, kurang baik 4 responden serta kriteria tidak baik tidak ada. Berdasarkan pada Tabel 2 diperoleh mean sebesar 39,16 yang terletak pada interval 38 - 46 dalam kriteria sangat baik. Maka dapat disimpulkan bahwa tingkat variabel perekonstruksi kebijakan (X1) termasuk dalam kriteria sangat baik.

Tabel 4. Distribusi Frekuensi Variabel Penentu Arah (X2)

\begin{tabular}{ccc|c}
\hline No. & Kategori & Interval & Frekuensi \\
\hline $\mathbf{1}$ & Sangat Baik & $52-64$ & 102 \\
$\mathbf{2}$ & Baik & $40-51$ & 34 \\
$\mathbf{3}$ & Kurang Baik & $28-39$ & 4 \\
$\mathbf{4}$ & Tidak Baik & $16-27$ & 0 \\
\hline
\end{tabular}

Berdasarkan Tabel 4. dapat dijelaskan bahwa tingkat variabel penentu arah diperoleh kriteria sangat baik dengan frekuensi 102 responden, baik 34 responden, kurang baik 4 responden serta kriteria tidak baik tidak ada. Berdasarkan pada Tabel 2 diperoleh mean sebesar 55,94 yang terletak pada interval 52-64 dalam kriteria sangat baik. Maka dapat disimpulkan bahwa tingkat variabel penentu arah (X2) termasuk dalam kriteria sangat baik.

Tabel 5. Distribusi Frekuensi Variabel Agen Perubahan (X3)

\begin{tabular}{ccc|c}
\hline No. & Kategori & Interval & Frekuensi \\
\hline $\mathbf{1}$ & Sangat Baik & $47-57$ & 101 \\
$\mathbf{2}$ & Baik & $36-46$ & 37 \\
$\mathbf{3}$ & Kurang Baik & $25-35$ & 2 \\
$\mathbf{4}$ & Tidak Baik & $14-24$ & 0 \\
\hline
\end{tabular}

Berdasarkan Tabel 5. dapat dijelaskan bahwa tingkat variabel agen perubahan diperoleh kriteria sangat baik dengan frekuensi 101 responden, baik 37 responden, kurang baik 2 responden serta kriteria tidak baik tidak ada. Berdasarkan pada Tabel 2 diperoleh mean sebesar 49,39 yang terletak pada interval 47-57 dalam kriteria sangat baik. Maka dapat disimpulkan bahwa tingkat variabel agen perubahan (X3) termasuk dalam kriteria sangat baik.

Tabel 6. Distribusi Frekuensi Variabel Juru Bicara (X4)

\begin{tabular}{ccc|c}
\hline No. & Kategori & Interval & Frekuensi \\
\hline $\mathbf{1}$ & Sangat Baik & $34-41$ & 102 \\
$\mathbf{2}$ & Baik & $26-33$ & 37 \\
$\mathbf{3}$ & Kurang Baik & $18-25$ & 1 \\
$\mathbf{4}$ & Tidak Baik & $10-17$ & 0 \\
\hline
\end{tabular}

Berdasarkan Tabel 6. dapat dijelaskan bahwa tingkat variabel juru bicara diperoleh kriteria sangat baik dengan frekuensi 102 responden, baik 37 responden, kurang baik 1 responden serta kriteria tidak baik tidak ada. Berdasarkan pada Tabel 2 diperoleh mean sebesar 35,36 yang terletak pada interval 34 - 41 dalam kriteria sangat baik. Maka dapat disimpulkan bahwa tingkat variabel juru bicara (X4) termasuk dalam kriteria sangat baik.

Tabel 7. Distribusi Frekuensi Variabel Pelatih (X5)

\begin{tabular}{ccc|c}
\hline No. & Kategori & Interval & Frekuensi \\
\hline $\mathbf{1}$ & Sangat Baik & $47-57$ & 93 \\
$\mathbf{2}$ & Baik & $36-46$ & 45 \\
$\mathbf{3}$ & Kurang Baik & $25-35$ & 2 \\
$\mathbf{4}$ & Tidak Baik & $14-24$ & 0 \\
\hline
\end{tabular}


Berdasarkan Tabel 8 dapat dijelaskan bahwa tingkat variabel kesiapan guru dalam menyongsong RI 4.0 diperoleh kriteria sangat baik dengan frekuensi 105 responden, baik 34 responden, kurang baik 1 responden serta kriteria tidak baik tidak ada. Berdasarkan pada Tabel 2 diperoleh mean sebesar 120,93 yang terletak pada interval 116-142 dalam kriteria sangat baik. Maka dapat disimpulkan bahwa tingkat variabel kesiapan guru menyongsong RI $4.0(\mathrm{Y})$ termasuk dalam kriteria sangat baik.

\section{Evaluating the Measurement Model}

Pemodelan persamaan struktural SEM dilakukan menggunakan SEM AMOS 24. Metode ini membantu peneliti untuk membangun model hubungan yang kompleks dan dapat digunakan untuk menganalisis pengaruh langsung dan tidak langsung. [18], [19]. Model pengukuran membahas dan mengevaluasi reliabilitas dan validitas indikator untuk mengukur kontruks hipotetis, sedangkan model struktural membahas hubungan antar variabel yang tidak teramati dan berkaitan dengan hubungan kausal antar variabel sesuai dengan hipotesis yang diajukan [18], [20] .

Validitas model pengukuran tergantung pada penetapan tingkat goodness of fit yang dapat diterima untuk model, dan menemukan bukti spesifik validitas konstruk. Untuk mengevaluasi validitas model pengukuran, yakni dilakukan pengujian terhadap validitas konstruk, yakni validitas konvergen. Variabel peran kepemimpinan visioner kepala sekolah yakni Perekontruksi kebijakan (X1), Penentu arah (X2), Agen perubahan (X3), Juru bicara (X4), Pelatih (X5) dan variabel kesiapan guru dalam menyongsong RI 4.0 (Y) diukur menggunakan 29 indikator.

Validitas konvergen model dievaluasi melalui Confirmatory Factor Analysis (CFA) menggunakan AMOS 24. Indikator yang memiliki nilai loading $>0,50$ diikutkan dalam pengujian [18], serta ukuran AVE (Average Variance Extracted) di syaratkan $>0,50$. Reliabilitas dinilai berdasarkan Composite Reliability (CR) $>0,70$. Tabel 9 menunjukkan validitas konvergen dan reliabilitas internal memuaskan, karena nilai loading faktor, CR dan AVE memenuhi dan signifikan.

Tabel 9. Results of the Measurement Model

\begin{tabular}{|c|c|c|c|c|}
\hline Factor & Item Code & Loading & AVE & $\mathrm{CR}$ \\
\hline \multirow[t]{5}{*}{ Perekontruksi Kebijakan } & RP1 & 0,769 & 0,643 & 0,900 \\
\hline & $\mathrm{RP}_{2}$ & 0,853 & & \\
\hline & RP3 & 0,825 & & \\
\hline & RP4 & 0,765 & & \\
\hline & RP5 & 0,793 & & \\
\hline \multirow[t]{4}{*}{ Penentu Arah } & DS1 & 0,865 & 0,689 & 0,898 \\
\hline & DS2 & 0,830 & & \\
\hline & DS3 & 0,849 & & \\
\hline & DS4 & 0,773 & & \\
\hline \multirow[t]{5}{*}{ Agen Perubahan } & $\mathrm{AoCl}$ & 0,716 & 0,598 & 0,881 \\
\hline & $\mathrm{AoC} 2$ & 0,817 & & \\
\hline & Aoc3 & 0,769 & & \\
\hline & $\mathrm{AoC} 4$ & 0,788 & & \\
\hline & Aoc5 & 0,773 & & \\
\hline \multirow[t]{5}{*}{ Juru Bicara } & SP1 & 0,782 & 0,610 & 0,886 \\
\hline & SP2 & 0,777 & & \\
\hline & SP3 & 0,716 & & \\
\hline & SP4 & 0,801 & & \\
\hline & SP5 & 0,824 & & \\
\hline \multirow[t]{7}{*}{ Pelatih } & $\mathrm{Cl}$ & 0,733 & 0,575 & 0,904 \\
\hline & $\mathrm{C}_{2}$ & 0,722 & & \\
\hline & C3 & 0,715 & & \\
\hline & $\mathrm{C} 4$ & 0,856 & & \\
\hline & C5 & 0,767 & & \\
\hline & $\mathrm{C} 6$ & 0,732 & & \\
\hline & c7 & 0,773 & & \\
\hline Kesiapan Guru & TR1 & 0,744 & 0,571 & 0,800 \\
\hline \multirow[t]{2}{*}{ Menyongsong RI 4.0} & TR2 & 0,793 & & \\
\hline & $\mathrm{TR}_{3}$ & 0,729 & & \\
\hline
\end{tabular}


Tabel 10. Inter-Correlations

\begin{tabular}{lcccccc}
\hline Factor & 1 & 2 & 3 & 4 & 5 & 6 \\
\hline 1. Perekontruksi Kebijakan & 0,643 & & & & & \\
2. Penentu Arah & 0,593 & 0,689 & & & & \\
3. Agen Perubahan & 0,617 & 0,668 & 0,598 & & & \\
4. Juru Bicara & 0,622 & 0,619 & 0,573 & 0,610 & & \\
5. Pelatih & 0,579 & 0,587 & 0,526 & 0,569 & 0,575 & \\
6. Kesiapan Guru Menyongsong RI 4.0 & 0,604 & 0,653 & 0,544 & 0,591 & 0,539 & 0,571 \\
\hline Note: N=134 & & & & & & \\
\hline
\end{tabular}

Tabel 11. The Fit Indices of the Model

\begin{tabular}{lllll}
\hline No. Goodness of Fit Indices & Hasil Uji Model & Cut-OffValue & Keterangan \\
\hline 1 & RMSEA & 0,059 & Mendekati nilai "0" & Baik \\
2 & DF & 1,488 & $<5$ & Baik \\
3 & IFI & 0,951 & Mendekati nilai "1" & Baik \\
3 & TLI & 0,941 & Mendekati nilai "1" & Baik \\
4 & CFI & 0,950 & Mendekati nilai "1" & Baik \\
\hline
\end{tabular}

Validitas diskriminan mengacu pada sejauh mana suatu konstruk benar-benar berbeda dari konstruk lainnya, tujuan utamanya yakni untuk membangun konsistensi internal. Penelitian ini dalam pengukuran validitas diskriminan dengan cara membandingkan AVE dengan squared correlation antara dua kontruks, dimana nilai AVE harus lebih besar dari nilai squared correlation antara dua kontruks [21]. Tabel 10 menunjukkan bahwa nilai AVE lebih besar daripada nilai squared correlation antara dua konstruks. Goodness of fit indices ditemukan dapat diterima seperti yang ditunjukkan pada Tabel 5.10. Berdasarkan Tabel 11, dapat dilihat bahwa semua indeks berada dalam kriteria yang direkomendasikan, yakni IFI= 0,$951 ; \mathrm{DF}=1,488 ; \mathrm{TLI}=0,941 ; \mathrm{CFI}=0,950 ; \mathrm{RMSEA}=0,059$.

\section{Evaluating the Structural Model}

Tujuan dari penelitian ini yakni untuk menguji pengaruh variabel peran kepemimpinan visioner kepala sekolah yakni Perekontruksi kebijakan (X1), Penentu arah (X2), Agen perubahan (X3), Juru bicara (X4), Pelatih (X5) dan variabel kesiapan guru dalam menyongsong RI 4.0 (Y). Gambar 2 menunjukkan hasil dari pengujian SEM menggunakan bantuan aplikasi AMOS 24. Berdasarkan evaluasi model pengukuran yang dijelaskan sebelumnya, langkah selanjutnya yang harus dilakukan yakni interpretasi model. Hasil pengujian hipotesis penelitian dan ringkasan hubungan antar variabel penelitian dapat dilihat pada Tabel 12 dan Tabel 13. 


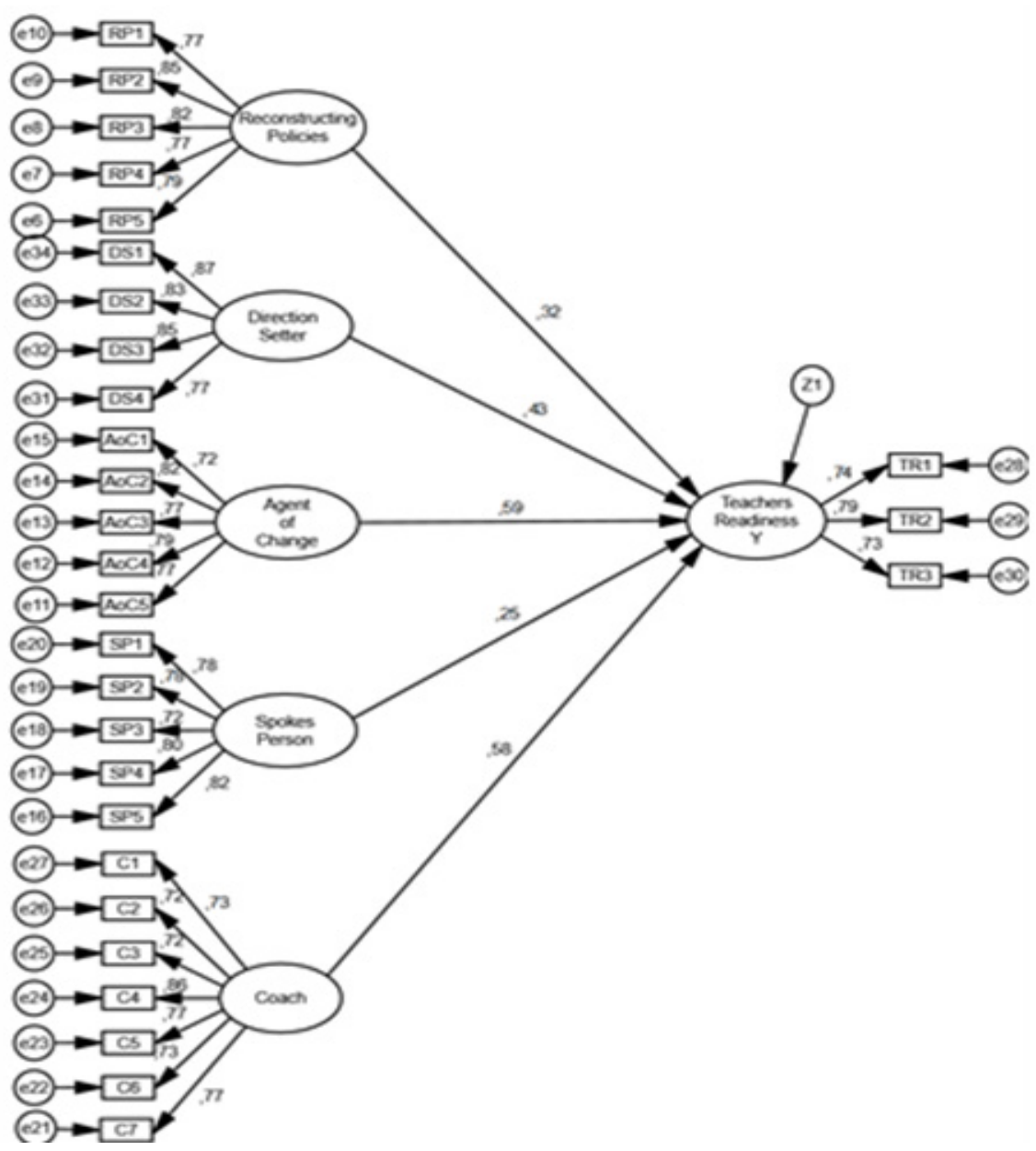

Gambar 2. Hasil Pengujian SEM

Tabel 12. Hasil Pengujian Hipotesis

\begin{tabular}{|c|c|c|c|c|}
\hline Variabel & Hipotesis & Phitung & Cut of Value & Keputusan \\
\hline$Y \leftarrow X 1$ & $\begin{array}{l}\text { Ho: Tidak ada hubungan antara } \\
\text { variabel X1 terhadap Y } \\
\text { H1: Ada hubungan antara variabel } \\
\text { X1 terhadap Y }\end{array}$ & 0,000 & 0,050 & HI diterima \\
\hline$Y \in X_{2}$ & $\begin{array}{l}\mathrm{H}_{0} \text { : Tidak ada hubungan antara } \\
\text { variabel } \mathrm{X} 2 \text { terhadap } \mathrm{Y} \\
\mathrm{H} 1 \text { : Ada bubungan antara variabel } \\
\mathrm{X} 2 \text { dan } \mathrm{Y}\end{array}$ & 0,000 & 0,050 & H1 diterima \\
\hline $\mathrm{Y} \leftarrow \mathrm{X} 3$ & $\begin{array}{l}\mathrm{H}_{6} \text { : Tidak ada hubungan antara } \\
\text { variabel } \mathrm{X} 3 \text { terhadap } \mathrm{Y} \\
\mathrm{H} 1 \text { : Ada hubungan hubungan } \\
\text { antara variabel X3 terhadap } \mathrm{Y}\end{array}$ & 0,000 & 0,050 & H1 diterima \\
\hline$Y \leftarrow X 4$ & $\begin{array}{l}\mathrm{H}_{0} \text { : Tidak ada hubungan antara } \\
\text { variabel } \mathrm{X} 4 \text { terhadap } \mathrm{Y} \\
\mathrm{H} 1 \text { : Ada hubungan antara variabel } \\
\mathrm{X} 4 \text { terhadap } \mathrm{Y}\end{array}$ & 0,012 & 0,050 & H1 diterima \\
\hline$Y \leftarrow X 5$ & $\begin{array}{l}\text { Ho: Tidak ada hubungan antara } \\
\text { variabel X5 terhadap Y } \\
\text { H1: Ada hubungan antara variabel } \\
\text { XS terhadap Y }\end{array}$ & 0,000 & 0,050 & H1 diterima \\
\hline $\begin{array}{l}\mathrm{Y} \leftarrow \mathrm{X} 5 \\
\operatorname{dan} \mathrm{X} 4 \\
\mathrm{X} 3, \mathrm{X} 2 \\
\mathrm{X} 1\end{array}$ & $\begin{array}{l}\mathrm{H}_{0}: \text { Tidak ada hubungan antara } \\
\text { variabel X1, X2, X3, X4, dan X5 } \\
\text { terhadap variabel } \mathrm{Y} \\
\mathrm{H} 1 \text { : Ada hubungan antara variabel } \\
\mathrm{X} 1, \mathrm{X} 2, \mathrm{X} 3, \mathrm{X} 4 \text {, dan } \mathrm{X} 5 \text { terhadap } \\
\text { variabel } \mathrm{Y}\end{array}$ & 0,000 & 0,050 & H1 diterima \\
\hline
\end{tabular}


Tabel 13. Ringkasan Hubungan antar Variabel Penelitian

\begin{tabular}{lll}
\hline No. & Variabel & Koefisien Jalur $(\beta)$ \\
\hline 1 & $\mathrm{Y} \leftarrow \mathrm{X} 1$ & 0,324 \\
2 & $\mathrm{Y} \leftarrow \mathrm{X} 2$ & 0,434 \\
3 & $\mathrm{Y} \leftarrow \mathrm{X} 3$ & 0,588 \\
4 & $\mathrm{Y} \leftarrow \mathrm{X} 4$ & 0,253 \\
5 & $\mathrm{Y} \leftarrow \mathrm{X} 5$ & 0,580 \\
6 & $\mathrm{Y} \leftarrow \mathrm{X} 5 \operatorname{dan} \mathrm{X} 4, \mathrm{X} 3, \mathrm{X} 2, \mathrm{X} 1$ & 0,326 \\
\hline
\end{tabular}

Berdasarkan Tabel 12 dan Tabel 13, diperoleh interpretasi hasil analisis sebagai berikut.

1) Variabel perekonstruksi kebijakan (X1) memiliki kontribusi langsung dengan kesiapan guru dalam menyongsong RI 4.0 (Y), dengan besar pengaruh 0,324 atau sebesar 32,4\%.

2) Variabel penentu arah (X2) memiliki kontribusi langsung dengan kesiapan guru dalam menyongsong RI $4.0(\mathrm{Y})$, dengan besar pengaruh 0,434 atau sebesar $43,4 \%$.

3) Variabel agen perubahan (X3) memiliki kontribusi langsung dengan kesiapan guru dalam menyongsong RI $4.0(\mathrm{Y})$, dengan besar pengaruh 0,588 atau sebesar 58,8\%.

4) Variabel juru bicara (X4) memiliki kontribusi langsung dengan kesiapan guru dalam menyongsong RI $4.0(\mathrm{Y})$, dengan besar pengaruh 0,253 atau sebesar 25,3 \%.

5) Variabel pelatih (X5) memiliki kontribusi langsung dengan kesiapan guru dalam menyongsong RI $4.0(\mathrm{Y})$, dengan besar pengaruh 0,580 atau sebesar $58 \%$.

6) Variabel perekonstruksi kebijakan (X1), penentu arah (X2), agen perubahan (X3), juru bicara (X4), dan pelatih (X5) memiliki kontribusi langsung secara bersama-sama terhadap kesiapan guru dalam menyongsong RI $4.0(\mathrm{Y})$, dengan besar pengaruh 0,326 atau sebesar 32,6\%.

\section{PEMBAHASAN}

Tidak ada konsep yang lebih kuat yang dapat diterima dalam usaha perbaikan sekolah dan reformasi sistem persekolahan di era revolusi industri 4.0 selain kepemimpinan [22]. Penciptaan sekolah yang efektif membutuhkan kepemimpinan kepala sekolah yang tepat di era digital seperti saat ini. Tantangan yang dihadapi dunia pendidikan pada era revolusi industri 4.0 antara lain terkait dengan kemampuan guru mengembangkan inovasi untuk meningkatkan hasil pembelajaran [8], oleh karena itu, penting bagi kepala sekolah untuk menyiapkan para guru menyongsong era revolusi industry 4.0 agar dapat menjalan tugas mengoptimalkan pembelajaran dengan lebih baik

Berdasarkan hasil penelitian ini variabel peran kepemimpinan visioner kepala sekolah yakni perekonstruksi kebijakan (X1), penentu arah (X2), agen perubahan (X3), juru bicara (X4), dan pelatih (X5) secara simultan memiliki pengaruh terhadap kesiapan guru dalam menyongsong RI 4.0. Untuk dapat menjalankan kepemimpinan secara efektif, seorang pemimpin visioner harus mengetahui peran yang harus dijalankan olehnya, sehingga dalam menjalankan tugas untuk mencapai tujuan organisasi tidak terjadi penumpukan peran. Terdapat empat peran yang harus dimainkan oleh pemimpin visioner dalam melaksanakan kepemimpinannya, yaitu; Peran penentu arah (direction setter); Agen perubahan (agent of change) ;Juru bicara (spokesperson); Pelatih (coach) [23], [24].

Kepemimpinan yang kuat dan visioner serta inovatif adalah yang dapat membuat organisasi bertahan hidup dan berkembang walaupun penuh dengan tantangan. Era globalisasi seperti saat ini membutuhkan kepemimpinan yang berkarakter sosial (social leadership), politic (political leadership), dan negarawan (state leadership) dalam mentranfomasikan berbagai masukan dari berbagai aspek kehidupan kedalam bentuk kebijakan dan untuk mewujudkan pelaksanaannya yang berdaya guna [25]. Kepala sekolah harus mampu mengkonstruksi kebijakan yang tepat dalam rangka penyiapan guru menyongsong revolusi industri 4.0. perekonstruksian kebijakan yang dilakukan kepala sekolah dilakukan melalui perumusan visi sekolah, perumusan kebijakan sekolah berdasarkan visi yang dibuat serta kebijakan pemerintah, 
rekonstruksi kebijakan pengembangan sekolah, dan penyusunan rencana pengembangan sekolah.

Peran ini merupakan peran di mana seorang pemimpin menyajikan suatu visi, meyakinkan gambaran atau target untuk suatu organisasi, guna diraih pada masa depan, dan melibatkan orang-orang dari get-go [24]. Hal ini bagi para ahli dalam studi dan praktek kepemimpinan merupakan esensi dari kepemimpinan. Sebagai penentu arah, seorang pemimpin menyampaikan visi, mengkomunikasikannya, memotivasi pekerja dan rekan, serta meyakinkan orang bahwa apa yang dilakukan merupakan hal yang benar, dan mendukung partisipasi pada seluruh tingkat dan pada seluruh tahap usaha menuju masa depan [26]. Kesiapan guru dalam menghadapi Revolusi Industri 4.0 dipengaruhi oleh kemampuan kepala sekolah dalam menerjemahkan visi agar dapat mudah dipahami oleh guru.

Sebagai juru bicara visi menghubungkan visi orang-orang lain dengan cara persuasif yang dapat mempengaruhi mereka untuk mengubah persepsi tentang apa yang penting bagi mereka dan bagi organisasi [27]. Dalam konteks ini pemimpin merumuskan visi yang akan digunakan oleh organisasi. Nilai dalam visi itu yang senantiasa dikembangkan kepada seluruh anggota organisasi agar mereka turut mengubah persepsinya yang semula bersikap apatis terhadap kinerja pelayanan umum menjadi baik. Fungsi komunikasi menjadi sarana yang efektif dalam mentransformasi informasi dan nilai-nilai visi kepada seluruh anggota maupun secara eksternal kepada pelanggan/masyarakat [28]. Disamping itu pemimpin juga harus membangun jaringan kerjasama yang erat dengan seluruh stakeholders di dalam dan di luar organisasi pemerintahan, baik swasta, lembaga swadaya masyarakat, pengusaha dan lainlain.

Tujuan pemimpin sebagai agen perubahan visi adalah menghasilkan keputusan-keputusan investasi dan perubahan-perubahan organisasional lainnya yang diperlukan dalam merealisasikan visi [27], [29]. Keahlian dan kemampuan pemimpin dalam mengelola dan mengarahkan perubahan menjadi sarana yang baik dalam mempengaruhi perilaku orang lain untuk turut dalam perubahan tersebut. Berpikir strategis, untuk menentukan langkah-langkah apa saja yang perlu dilakukan dalam mewujudkan visi dan perubahan, dengan membuat kebijakan strategis. Selain itu membangun iklim organisasi yang dinamis dan kondusif, sehingga perubahan visi tidak lagi menjadi barang asing tetapi menjadi bagian dalam organisasi.

Pemimpin visioner yang efektif harus menjadi pelatih yang baik [23]. Dengan ini berarti bahwa seorang pemimpin harus menggunakan kerjasama kelompok untuk mencapai visi yang dinyatakan. Seorang pemimpin mengoptimalkan kemampuan seluruh staf untuk bekerja sama, mengkoordinir aktivitas atau usaha mereka, ke arah pencapaian kemenangan, atau menuju pencapaian suatu visi organisasi. Pemimpin, sebagai pelatih, menjaga pekerja untuk memusatkan pada realisasi visi dengan pengarahan, memberi harapan, dan membangun kepercayaan di antara pemain yang penting bagi organisasi dan visinya untuk masa depan.

Peran yang harus dijalankan kepala sekolah visioner sejalan dengan pandangan yang menyatakan bahwa kepemimpinan visioner kepala sekolah diperlukan bahwa mereka harus memiliki kompetensi dalam menentukan visi yang tepat [30]. Kepala sekolah harus menginspirasi kreativitas staf, dan menggunakan kekuatan insentif untuk memimpin staf mereka untuk bekerja, agar sukses mencapai tujuan. Selain itu, kepala sekolah harus memimpin staf mereka menjauhi pemikiran tradisional, untuk menjangkau masa depan, mentransfer pemikiran, komunikasi, dan informasi secara jelas, serta mengembangkan potensi staf terus menerus untuk memanfaatkan pengetahuan mereka dan kompetensi untuk sekolah [24], [31]-[33].

Faktor yang mempengaruhi keberhasilan sekolah efektif tersebut, dua di antaranya adalah kepemipinan kepala sekolah dan kinerja guru. Karena keduanya merupakan tonggak terpenting semua aktifitas sekolah termasuk di era revolusi industry 4.0. Di sekolah efektif, antara kepemimpinan kepala sekolah berhubungan dengan kinerja guru [34]. Di sekolah efektif ada tiga komponen yang saling melengkapi dan tidak terpisahkan [35], [36]. Pertama adalah human capital (modal manusia). Hal ini terkait dengan kompetensi manusia di sekolah sebagai pendidik. Kedua, modal sosial, hubungan di sekolah terus diperkuat dan berkembang dalam rangka untuk memungkinkan setiap individu mampu mengaktualisasikan pengetahuan dan keterampilannya. Disamping itu modal sosial dapat dimaknai 
terjalinnya hubungan antara sekolah dan masyarakat untuk melaksanaan program sekolah yang lebih baik. Komponen terakhir adalah penyelarasan [37], karena meskipun banyak ide-ide inovatif dan baru selalu muncul, sekolah dapat menjadi paling efektif ketika mereka tidak hanya mengambil inovasi yang bagus, tetapi mereka yang mampu mengintegrasikan, menyelaraskan dan mengkoordinasikan inovasi tersebut ke dalam program mereka sendiri serta fokus dalam mengimplementasikannya.

\section{SIMPULAN}

Berdasarkan hasil penelitian di atas, maka kesimpulan dari penelitian ini sebagai berikut: (1) Tingkat variabel peran kepemimpinan visioner kepala sekolah yakni perekonstruksi kebijakan (X1), penentu arah (X2), agen perubahan (X3), juru bicara (X4), dan pelatih (X5) berada pada kategori sangat baik, serta tingkat variabel kesiapan guru dalam menyongsong RI 4.0 berada pada kategori sangat baik; (2) Variabel perekonstruksi kebijakan memiliki kontribusi langsung dengan kesiapan guru dalam menyongsong RI 4.0; (3) Variabel penentu arah memiliki kontribusi langsung dengan kesiapan guru dalam menyongsong RI 4.0; (4) Variabel agen perubahan memiliki kontribusi langsung dengan kesiapan guru dalam menyongsong RI 4.0; (5) Variabel juru bicara memiliki kontribusi langsung dengan kesiapan guru dalam menyongsong RI 4.0; (6) Variabel pelatih memiliki kontribusi langsung dengan kesiapan guru dalam menyongsong RI 4.0; dan (7) Variabel peran kepemimpinan visioner kepala sekolah yakni perekonstruksi kebijakan (X1), penentu arah (X2), agen perubahan (X3), juru bicara (X4), dan pelatih (X5) secara simultan memiliki pengaruh terhadap kesiapan guru dalam menyongsong RI 4.0.

\section{DAFTAR RUJUKAN}

[1] K. B. Boal and R. Hooijberg, "Strategic Leadership Research: Moving on," Leadersh. Q., vol. 11, no. 4, pp. 515-549, 2000.

[2] M. Parco-Tropicales and A. B. de Guzman, "A Structural Equation Model (SEM) of the Impact of Transformational, Visionary, Charismatic and Ethical Leadership Styles on the Development of Wise Leadership among Filipino Private Secondary School Principals,” Asia Pacific Educ. Rev., vol. 15, no. 4, pp. 547-559, 2014.

[3] W. Setiawan, "Peran Kepemimpinan Visioner Untuk Menghasilkan Calon Pendidik Yang Berkarakter Kuat dan Cerdas Di Fakultas Keguruan Dan Ilmu Pendidikan (Fkip) Uns Surakarta," UNS, 2009.

[4] G. J. Tellis, "Disruptive technology or visionary leadership?," J. Prod. Innov. Manag., vol. 23, no. 1, pp. 34-38, 2006.

[5] T. Wallner and G. Wagner, “Academic Education 4.0,” Int. Conf. Educ. New Dev., vol. June, pp. 155-159, 2016.

[6] D. A. Stam, D. van Knippenberg, and B. Wisse, "The Role of Regulatory Fit in Visionary Leadership," J. Organ. Behav., vol. 31, no. 4, pp. 499-518, 2010.

[7] M. Haigh, F. Ell, and V. Mackisack, "Judging Teacher Candidates' Readiness to Teach," Teach. Teach. Educ., vol. 34, no. August, pp. 1-11, 2013.

[8] T. Wanyama, "Using Industry 4.0 Technologies to Support Teaching and Learning," Int. J. Eng. Educ., vol. 33 , no. 2, pp. 693-702, 2017.

[9] M. T. Greenberg, "School-Based Prevention: Current Status and Future Challenges," Eff. Educ., vol. 2, no. 1, pp. 27-52, 2010.

[10] "Pengembangan Iptek dan Pendidikan Tinggi di Era Revolusi Industri 4.0 - Kemenristek / BRIN." [Online]. Available: https://www.ristekdikti.go.id/siaran-pers/pengembangan-iptek-dan-pendidikan-tinggi-di-erarevolusi-industri-4-0/. [Accessed: 28-Oct-2019].

[11] C. M. Taylor, C. J. Cornelius, and K. Colvin, "Visionary Leadership and its Relationship to Organizational Effectiveness," Leadersh. Organ. Dev. J., vol. 35, no. 6, pp. 566-583, 2014.

[12] Sunnyvale School District, "7 Correlates of Effective Schools," 2009. [Online]. Available: https://www.sesd. org/Page/1001.

[13] J. C. Creswell, Research Design: Pendekatan Metode Kualitatif, Kuantitatif, dan Campuran. Yogyakarta: Pustaka, 2018. 
[14] M. Saunders, P. Lewis, and A. Thornhill, Research Methods for Business Students (7th Ed.), 7th ed. London: Pearson Education Limited, 2016.

[15] B. B. Wiyono, Metodologi Penelitian (Pendekatan Kuantitatif, Kualitatif, dan Action Research). Malang: FIP Universitas Negeri Malang, 2007.

[16] D. . Mertens, "Research and Evaluation in Education and Psychology Integrating Diversity With Quantitative, Qualitative, and Mixed Methods (3rd ed.)." Sage, California, 2009.

[17] Y. In’Nami and R. I. E. Koizumi, Structural Equation Modeling In Educational Research : a Primer. Rotterdam: Sense Publishers, 2013.

[18] J. . Hair, W. . Black, B. . Babin, and R. . Anderson, Multivariate Data Analysis (7th Ed.). New Jersey: Pearson Prentice Hall, 2009.

[19] S. Al-husseini and I. Elbeltagi, "Evaluating the effect of transformational leadership on knowledge sharing using structural equation modelling : the case of Iraqi higher education," Int. J. Leadersh. Educ., vol. 21, no. 4, pp. 506-517, 2018.

[20] B. Uslu and H. Arslan, "Faculty' s academic intellectual leadership : the intermediary relations with universities ' organizational components," Int. J. Leadersh. Educ., vol. 3124, no. April, pp. 1-13, 2017.

[21] C. Fornell and D. . Larcker, "Evaluating Structural Equation Models with Unobservable Variables and Measurement Error," J. Mark. Res., vol. 18, no. 1, pp. 39-50, 1981.

[22] A. Harris, “Teacher Leadership, ” in International Encyclopedia of the Social \& Behavioral Sciences: Second Edition, 2015, pp. 60-63.

[23] W. A. Giles and B. Nanus, "Visionary Leadership: Creating a Compelling Sense of Direction for Your Organization," Public Adm. Rev., vol. 54, no. 1, p. 87, 1994.

[24] B. Nanus, Visionary Leadership: Creating A Compelling Sense Of Direction For Your Organization. San Francisco, Ca: Jossey-Bass A Wiley Imprint, 1992.

[25] Ramli Muhammad, “Kepemimpinan Inovatif Dalam Implementasi Kebijakan Strategis Pemerintah,” JPP (Jurnal Polit. Profetik), vol. 5, no. 2, pp. 168-184, 2017.

[26] Y. Kondakci, K. Beycioglu, M. Sincar, and C. T. Ugurlu, "Readiness of Teachers for Change in Schools," Int. J. Leadersh. Educ., vol. 20, no. 2, pp. 176-197, 2017.

[27] Hadiwawan, “Kepemimpinan Visioner," 2014. [Online]. Available: http://hadiwawan.com. [Accessed: 31 Jan-2015].

[28] N. Azni, A. Aziz, and F. S. Fooi, "Literature Review on the Relationship Between Principal Instructional Leadership and Teacher Readiness To Implement Change," J. Arts, Sci. Commer, vol. 6, no. January, pp. 12-19, 2015.

[29] W. Abbas and I. Asghar, "The Role of Leadership in Organisational Change," University of Gavle, 2010.

[30] S. Kahan, “Leadership: Visionary Leadership, ”Seth Kahan's Visionary Leadership, 2008. [Online]. Available: https:/visionaryleadership.com/leadership-visionary-leadership/. [Accessed: 29-Oct-2019].

[31] S. Thompson, "Visionary Leadership in Action while there is More to Leadership than Vision," 2009. [Online]. Available: http//:www.books.google.co.th/ books?isbn=0761971777.

[32] S. Kapu, "Principles of Visonary Leadership," 2008. [Online]. Available: www.surinder.com. [Accessed: 17Feb-2016].

[33] S. Tepsaeng, "Visionary Leadership: New Model of School Administrators in Next Decade," J. Educ. Adm. Srinagarinwirote Univ., vol. 6, no. 11, pp. 83-95, 2009.

[34] A. C. Wright, "A Literature Review on the Determinants of Teacher Performance," Econ, vol. 250, no. 1, pp. $1-18,2012$.

[35] M. Fullan and N. Watson, "School-Based Management: Reconceptualizing to Improve Learning Outcomes," Sch. Eff. Sch. Improv., 2000.

[36] M. Fullan, “The Principal: Three Keys to Maximizing Impact,” J. Cathol. Educ., vol. 18, no. 1, pp. 208-211, 2014.

[37] D. Hopkins and D. Jackson, Building the capacity for leading and learning. InHarris, A., Day, C., Hadfield, M., Hopkins, D., Hargreaves, A. And Chapman, C. Effective Leadership for School Improvement. New York: Routledge Falmer, 2003. 